\title{
Qualitative Explanation of Cultural and Environmental Factors Reducing Organizational Silence in Social Service Organizations
}

\author{
Fereydoun Ahmadi ${ }^{1} \mathbb{D}$, Mazdak Jamshidi ${ }^{2} \mathbb{D}$, Ali Akbar Ahmadi ${ }^{3} \mathbb{D}$, Zahra Forootani ${ }^{4} \mathbb{D}$
}

Date of submission: 09 Dec. 2020 Date of acceptance: 16 Jan. 2021

\begin{abstract}
INTRODUCTION: The efficiency and development of any organization largely depend on the proper use of human resources. In today's organizations, to reduce organizational silence, employees express their ideas and share their views to increase organizational efficiency. This study was conducted to qualitatively explain the cultural and environmental factors that reduce organizational silence in government organizations.

METHODS: This applied study was conducted based on a descriptive-analytical approach and implemented through the field research method. The samples $(n=18)$ were selected among senior managers of government organizations using purposive sampling and the sample size required amount was based on theoretical saturation criterion. The required data were collected through holding interviews and they were analyzed using the grounded theory method.

FINDINGS: The results showed that the four selective codes of "progress", "appropriate cultural background", "lack of proper attribution" and "increasing culture in the field of teamwork" could explain the concept of organizational silence.

CONCLUSION: According to the results, the roots of the formation of this destructive and inhibitory organizational phenomenon are lied in the context of social, cultural, and political interactions, identified under the influence of "environmental and cultural factors", and started via social learning. These environmental and cultural factors can be programmed and corrected to guide and control organizational silence and direct the constructive voice of the organization.

Keywords: Organizational Silence; Cultural and Environmental Factors; Grounded Theory; Government Organizations.
\end{abstract}

Original Article

How to cite this article: Ahmadi F, Jamshidi M, Ahmadi AA, Forootani Z. Qualitative Explanation of Cultural and Environmental Factors Reducing Organizational Silence in Social Service Organizations. Sci J Rescue Relief 2021; 13(1): 1-8.

\section{Introduction}

$\mathrm{O}$ ne of the major problems currently facing organizations, especially in the human resources sector, is the reluctance of employees to participate in organizational discussions. Organizational silence is an inefficient organizational process that eliminates costs and efforts and can manifest in various forms, such as collective silence in a meeting, the low participation rate in polls, and low expression of ideas and opinions. When most staff in an organization prefer to remain silent about organizational issues, silence becomes a collective phenomenon called organizational silence. In today's changing world, organizations need employees who express their ideas. On the other hand, individuals choose organizations in which they can express their views. It has been revealed that both managers and employees show higher motivation and performance in an environment where there is no silence (1).

Human capital, which according to the majority of experts in management and organization fields, is one of the most valuable assets and as the most important coordinating resource of the

1-Associate Professor, Public Administration, Payame Noor University, Iran

2-PhD student, Public Management, Human Resources, Payame Noor University, Iran

3-Professor, Public Administration, Payame Noor University, Iran

4-Assistant Professor, Public Administration, Payame Noor University, Iran

Correspondence to: Mazdak Jamshidi, Email: mazdak.jamshidi@gmail.com 
organization, can be effective in the growth, vitality, and development or failure and collapse of the organization. In the current conditions, the organizations that can make the best use of these resources and their vital factors are more successful. Government organizations, in terms of the greater importance of time, level of impact on society, and all-round competition, need effective employees, active participation, and components of organi-zational behavior more than any other organization $(2,3)$.

Among the most important obstacles to the success of organizational programs and goals are the lack of information, trust, and effective organizational behavior that are interpreted as 'organizational silence' by researchers. In numerous organizations, there are no opportunities for employees to easily comment on the situations and problems and participate in the process of organizational improvement and promotion. In such a situation, employees behave silently and the organization will no longer be able to utilize these valuable resources.

Organizational silence is associated with limiting the effectiveness of organizational decisions and resistance against the processes of change in the organization and leadership. This is a problem that organizations are currently struggling with and causes most organizations to suffer from minimal employees' feedback. Organizational silence also hinders effective organizational changes and development by preventing negative feedback, resulting in the inability of the organization to review and correct mistakes $(4,5)$. If human capital and its constructive interactions are considered necessary and vital in all organizations, in the organizational world, it requires double importance due to the type of activity that is of influence, impact, and change on the attitude, feelings, and behavior of customers, as well as due to the variety and diversity of activities and the extent of competition in this field.

In the current environment, the capability and survival of government organizations largely depend on the emergence of talent, creativity, and knowledge, which originates from the active participation of human resources. Due to the nature of government organizations and the important and vital role that the employees of such organizations play in maintaining and surviving in today's competitive world, the issue of employees' silence and voice becomes much more prominent $(6,7)$.

The limiting of the quality of organizational decisions and slowing down the pace of changes in organizations are attributed to employees' resistance to change and lack of constructive feedback from employees, leading to the inability of the organization to correct its mistakes, reduction of job satisfaction, and reduction of the positive components of organizational citizenship behavior, followed by the loss of opportunities, customer trust and interest, and the extinction of ideas as the consequences of this type of organizational phenomenon.

The participation of intellectual capital is undeniable in gaining trust and mutual communication and the ability to form groups, and consolidate ideas, and create a sense of collective responsibility. The need to share intellectual property reserves in government organizations is important since it serves as a determining factor in the management of such organizations. The service unit in the organization is considered 'a moment' and the best and most rational decisions need to be made in the shortest time, which requires the maximum use of collective knowledge and participation (8).

The results of this study will enable managers and policymakers of the government organization system to try and plan for the dynamism and maturity of employees, as well as empowering them, establishing employees-managers trust, and obtaining individuals' opinions, according to the existing reality and the position of silence in the organization, and therefore, facilitate the realization of the goals of government organizations.

Government organizations as service organizations can achieve their ultimate goal of being effective on the customer in line with predetermined goals merely by relying on dynamic and creative human resources and benefiting from the active participation of employees in all areas of service, including service transfer and delivery. Consequently, following the path of organizational change, transformation, and learning in the complex and changing environment of the current organization requires recognizing the factors affecting human resources. In this regard, the investigation of environmental and cultural factors of organizational silence according to the consequences that it creates in the field of 
organizational behavior is one of the basic needs of government organizations in the path of organizational reform, agility, and dynamism. This study was conducted to qualitatively explain the cultural and environmental factors that reduce organizational silence in government organizations in 2020.

\section{Methods}

This qualitative study was conducted based on the grounded theory method. The required data regarding the effective factors on the reduction of organizational silence in government organizations were gathered through in-depth, semi-structured interviews. The statistical population of this study consisted of 18 senior managers of government organizations selected using the purposive sampling method. The interview questions were designed according to research questions and other similar research and modified with considering the experts' opinions. In the first stage of the study, the concepts, categories, and propositions were counted and organized by performing the three steps of data source coding using the Strauss and Corbin method. For this purpose, data sources were collected in a structured manner.

In this study, one of the main goals of government organizations, to promote employees' participation, was to identify environmental and cultural factors affecting the reduction of organizational silence of employees in these types of organizations. Based on this goal, the researcher started documentary research and then achieved the research findings by determining the grounded theory method and using in-depth interviews with community members. Subsequently, using open, axial, and selective coding steps, a theoretical model was formed in the researcher's mind. By obtaining the selected codes, a paradigm model was formed in the researcher's mind. In the first coding step, the interviews were carefully reviewed and key phrases were extracted from the interviewees' comments and then titled.

In the next step, according to the similar dimensions and characteristics of the resulting concepts and open codes, they were categorized in the form of a broader concept called central code, and finally, the researcher reached a paradigm model and answered the research questions. Afterward, the findings of the interviews were presented. The frequency rates of open, axial, and central codes obtained from each interview were determined. After open coding and acquiring the concepts in each text, a number of selective codes were selected by putting together similar concepts and central coding. The accuracy of the qualitative data was confirmed by Guba and Lincoln criteria (9).

\section{Findings}

In this study, the mean age of interviewees was estimated at 48 years, and 12 out of 18 subjects were male. The results of open, axial, selective, and central core coding are shown in Table1. Based on the abstraction and conceptualization of the interviews, four selective codes were obtained, including "progress", "appropriate cultural background", "lack of proper attribution", and "increasing culture in the field of teamwork". Achieving a dynamic organization is certainly ensured through constructive manpower, and this human capital grows in social, cultural, and environmental contexts and is nurtured through social learning and education at different levels. Therefore, numerous interviewees emphasized the high impact of this concept.

Figure 1 shows the selective codes affecting this central component.

The selective code for "appropriate cultural backgrounds" was derived from putting together the two axial codes of "cultural perceptions" and "increasing the culture of opinion expression in society". These two axial codes, as shown in Table 2, are obtained from similar concepts for the

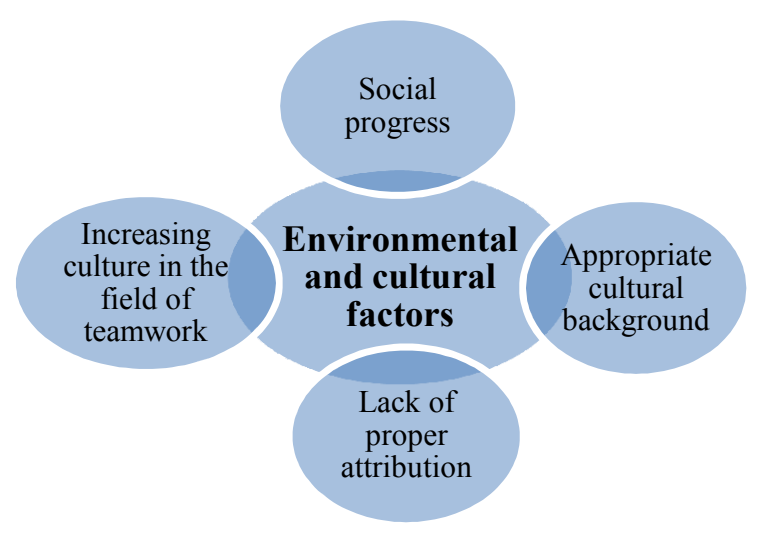

Figure 1. Environmental and cultural factors of silence 
Table 1. Open, axial, selective, central coding

\section{Open coding}

Axial coding

Selective coding

General group (central core)

Existence of a rational-focused

environment in society and a suitable environment for expressing opinions

Encouragement in the organization to express ideas and opinions

Strong culture for criticizing and receiving feedback

Encouragement to expressing opinions and responsibility

Lack of spread of despair environment and social distrust/transmission of lies, embezzlement, and inequalities

Cultural beliefs/lack of emphasis on conservative practices

Increasing the culture of opinion expression in society

Cultural perceptions

Increasing culture in the field of teamwork

Organizations' interest in group order/lack of interest in divisive and governing behaviors

Desire to work collectively

Strong educational system and its evaluation system in behavior modification

High level of knowledge and literacy of the society

Open verbal and communication structures

Advanced structures

Lack of past authoritarian social and political structures

Belief or disbelief in the prevailing values

Lack of fear of the opposite label

Political considerations / in line with or in contrast to prevailing political approaches

Lack of fear of social and political consequences
Increase science and knowledge
Appropriate cultural background

Increasing culture in the field of teamwork

Social progress
Lack of proper attribution
Lack of proper attribution

Environmental and cultural factors 
Table 2. Selective code of appropriate cultural backgrounds

\begin{tabular}{|c|c|c|c|}
\hline Open coding & Axial coding & $\begin{array}{l}\text { Selective } \\
\text { coding }\end{array}$ & $\begin{array}{l}\text { General group } \\
\text { (central core) }\end{array}$ \\
\hline $\begin{array}{c}\text { Existence of a rational-focused environment in society and the } \\
\text { existence of a suitable environment for expressing opinions } \\
\text { Encouragement in the organization to express ideas and } \\
\text { opinions } \\
\text { Strong culture for criticizing and receiving feedback } \\
\text { Courage in expressing opinions and responsibility } \\
\text { Lack of spread of despair environment and social } \\
\text { distrust/transmission of lies, embezzlement, and inequalities } \\
\text { Cultural beliefs/lack of emphasis on conservative practices } \\
\text { Collective learning - reducing dual actions } \\
\text { Reduce high power distance }\end{array}$ & $\begin{array}{l}\text { Increasing the } \\
\text { culture of opinion } \\
\text { expression in } \\
\text { society }\end{array}$ & $\begin{array}{l}\text { Appropriate } \\
\text { cultural } \\
\text { backgrounds }\end{array}$ & $\begin{array}{l}\text { Environmental } \\
\text { and cultural } \\
\text { factors }\end{array}$ \\
\hline
\end{tabular}

abstraction of these codes. According to the interviewees, cultural beliefs and contexts had a significant impact on individuals' silence.

The selection of cultural unclean backgrounds with negative implications can convey the negative impact of the concepts in the infrastructure of this selective code.

"Cultural perceptions" and "increasing the culture of expression in society" are the two central codes making up this selective code. Moreover, the categories of "existence of a rational-focused environment in society and a suitable environment for expressing opinions", "encouragement to expressing opinions and responsibility", "strong culture for criticizing and receiving feedback", "courage in expressing opinions and responsibility", "lack of spread of despair environment and social distrust/transmission of lies, embezzlement, and inequalities", "Cultural beliefs / Lack of emphasis on conservative practices", "collective learning - reducing dual actions", and "reduce high power distance" were found to be among the concepts and categories extracted from the interviewees' opinions.

Some excerpts from interviewees' opinions about appropriate cultural backgrounds are provided as examples to better understand the importance of the topic:

- Existence of a rational-focused environment in society: "Our society is not based on intellectualism and there is no suitable environment for creativity and not being silent in the whole society and following those organizations."

- Encouragement in the organization to express ideas and opinions: "Despite the various facilities, we did not use media tools properly to change and modify the situation and tried to ignore the issues for face-saving."

The selective code of "increasing culture in the field of teamwork", as shown in Table 3, is derived from similar concepts for the abstraction of these codes. The strong culture of teamwork and attention to collective interests were among the reasons that, according to the interviewees, were effective in reducing organizational silence. Some excerpts from the interviewees' opinions regarding increasing culture in the field of teamwork are given as examples to better understand the importance of the topic:

Existence of adequate training in collective work: "In government organizations, there is no training for collective cooperation and maintenance of group interests. Rather,

Table 3. Selective code for increasing culture in the field of teamwork

\begin{tabular}{|c|c|c|c|}
\hline Open coding & Axial coding & $\begin{array}{l}\text { Selective } \\
\text { coding }\end{array}$ & $\begin{array}{l}\text { General group } \\
\text { (central core) }\end{array}$ \\
\hline $\begin{array}{c}\text { Reduce harmful competition/conflicts } \\
\text { Adequate training in teamwork } \\
\text { Reluctance to emphasize oneself / diminish personal interests } \\
\text { Organizational interest in group order / and lack of interest in } \\
\text { divisive and governing behaviors } \\
\text { Desire to work collectively }\end{array}$ & $\begin{array}{l}\text { Increasing } \\
\text { culture in the } \\
\text { field of } \\
\text { teamwork }\end{array}$ & $\begin{array}{l}\text { Increasing } \\
\text { culture in the } \\
\text { field of } \\
\text { teamwork }\end{array}$ & $\begin{array}{l}\text { Environmental } \\
\text { and cultural } \\
\text { factors }\end{array}$ \\
\hline
\end{tabular}


Table 4. Selective code of social progress

\begin{tabular}{|c|c|c|c|}
\hline Open coding & Axial coding & $\begin{array}{l}\text { Selective } \\
\text { coding }\end{array}$ & $\begin{array}{l}\text { General group } \\
\text { (central core) }\end{array}$ \\
\hline $\begin{array}{c}\text { Up-to-date structures } \\
\text { Open communication hierarchy } \\
\text { Lack of previous social and political authoritarian system } \\
\text { Strength of the educational system and its measurement } \\
\text { method in behavior change } \\
\text { High level of literacy and knowledge in the community }\end{array}$ & $\begin{array}{l}\text { Increase of } \\
\text { science and } \\
\text { knowledge }\end{array}$ & Social progress & $\begin{array}{l}\text { Environmental } \\
\text { and cultural } \\
\text { factors }\end{array}$ \\
\hline
\end{tabular}

individuals try to monopolize their work and, as a result, attribute them to themselves."

- Decrease in personal interests: "We all, from the highest to the lowest rank, are thinking of personal interests and self-promotion, and to outdo each other, we are willing to ruin each other."

The selective code of "social progress" is obtained by combining the two central codes of "progress" and "increase of science and knowledge". These two central codes, as shown in Table 4, are derived from similar concepts for the abstraction of these codes. The impact of these concepts on the level of comprehensive development of a society's infrastructure was very tangible in the interviewees' speeches.

Some excerpts of interviewees' conversations regarding social progress are provided as examples to better understand the importance of the topic:

- Lack of previous social and political authoritarian systems: "Living in authoritarian systems has established silence in individuals' minds."

- Increasing the level of literacy and knowledge of society: "The level of knowledge and literacy of society is effective in the creation of active behaviors of individuals. There is no plan for change; open-mindedness is not promoted by educational system and universities; moreover, and the assessment of the education system is not based in this regard."

The selective code of "lack of proper attribution", as shown in Table 5, is derived from similar concepts for the abstraction of these codes. According to the interviewees, the role of alignment with social and political considerations was effective in avoiding the wrong attribution and its consequences.

Some excerpts of the interviewees' remarks about lack of proper attribution are given as examples to better understand the importance of the topic:

- Lack of fear of opposite opinion: "If an individual expresses others' negative traits, they try to close his/her mouth with different labels, and people do not dare to endanger themselves and their families because of their fear."

- Lack of attention to political aspects: "The political approaches of the organization in the managerial and organizational hierarchy will cause silence or organizational participation, the alignment of political and factional approaches with each other and the connection of this approach to other areas, will ultimately see the benefit of performing things in its own interests and is quite active and even ignores shortcomings and problems. On the contrary, some individuals do not accept the organization with all its facilities since they do not believe in its approaches."

The model designed in this research is based on environmental and cultural factors, which is founded on the context of permanent environmental

Table 5. Selective code of lack of proper attribution

\begin{tabular}{|c|c|c|c|}
\hline Open coding & Axial coding & Selective coding & $\begin{array}{l}\text { General group } \\
\text { (central core) }\end{array}$ \\
\hline $\begin{array}{l}\text { Degree of uncertainty about dominant beliefs } \\
\text { Lack of fear of the opposite opinion }\end{array}$ & \multirow{3}{*}{$\begin{array}{l}\text { Lack of proper } \\
\text { attribution }\end{array}$} & \multirow{3}{*}{$\begin{array}{l}\text { Lack of proper } \\
\text { attribution }\end{array}$} & \multirow{3}{*}{$\begin{array}{l}\text { Environmental and } \\
\text { cultural factors }\end{array}$} \\
\hline $\begin{array}{l}\text { Political considerations / in line with or in contrast to } \\
\text { prevailing political approaches }\end{array}$ & & & \\
\hline Lack of fear of social and political consequences & & & \\
\hline
\end{tabular}


and organizational changes and considering the conditions of macro changes and organizational crises. Causal conditions are conditions that cause the occurrence of a phenomenon. According to the interviewees in the studied community, the weakness of the teamwork culture, attention to individual interests, lack of proper intragroup communications, desire to proceed individual's interests were highly influential and are considered as factors strengthening organizational isolation and silence.

\section{Discussion and Conclusion}

In current organizations, numerous employees are isolated and in practice reluctant to speak and express their opinion. Some managers consider this issue simple and think employees' reluctance to express their opinions and not participate in discussions is a kind of organizational satisfaction. Although in Iranian culture, silence has long been associated with consent (11), this issue is not limited to Iran. In general, the results of some studies indicated that the concept of silence was equated with commitment and loyalty. However, the findings of recent studies performed on silent employees emphasized the inability to achieve the expected performance and job dissatisfaction due to inactivity in the organization (12).

Although proper conditions have been provided to encourage employees to participate more in organizational environments, various organizations expect their staff to make only certain statements, especially about acknowledging the current state of the organization, and for this purpose, they implement a reward and punishment system (13). Furthermore, organizational silence inhibits effective change and organizational development by preventing negative feedback; therefore, the organization lacks the ability to check and correct mistakes. Without negative feedback, the rate of mistakes increases and even aggravates since corrective actions are not taken when necessary. Therefore, the silence and discouragement of employees towards the destiny and plans of the organization and the lack of effective employeemanagement understanding are warning signals indicating the reduction of organizational performance that harms society. As a result, organizational silence and finding ways to resolve it are of great importance in contemporary organizational issues and require serious attention of managers (10).

In government organizations, as the studied society, with regard to the description of tasks based on preparing conditions for the creation of intra-organizational relationships with the aim of strengthening the spirit of organizational understanding, empathy, partnership, and affiliation between employees and managers, it has been proposed to strengthen the components of participation and sense of belonging to the organization, which have been even emphasized to be included in the description of segregated duties of managers of government organizations.

The activity of government organizations in raising the constructive, dynamic, and participatory spirit among all employees of this type of organization is highly critical as a unit that seeks to link intra-organizational fields to achieve the goals and strategy of the organization in the external environment. Due to the rapid and diverse political, economic, social, and cultural changes that occur in the organization, it is necessary to design a mechanism within the organization that can timely predict developments, manage crises, strengthen competitive advantages, highlight social credibility and responsibility, and properly give directions to organizational culture. To this end, employees are the resources that can be invested in. Regarding environmental and cultural factors, the results of none of the found studies made a direct reference to these factors and had merely addressed them as underlying factors. Nevertheless, the findings of this research emphasized the impact of these factors on a large scale.

The results of the current research showed that the roots of the formation of this destructive and inhibitory organizational phenomenon are lied in the context of social, cultural, and political interactions, identified under the influence of "environmental and cultural factors", and started via social learning. These environmental and cultural factors can be programmed and corrected to guide and control organizational silence and direct the constructive voice of the organization. Nonetheless, at present, based on the findings, it seems that the focus of the management system of government organizations is directed to the issues 
outside of the organization, and the budget crisis and structural changes have overshadowed the focus on human resources. In any case, the achievement of these results and reflection on the research findings highlight the need to change attitudes in the field of human capital.

\section{Acknowledgments}

None

\section{Conflict of Interests}

Authors have no conflict of interests

\section{References}

1. Deniz N, Noyan A, Ertosun ÖG. The relationship between employee silence and organizational commitment in a private healthcare company. Proc Soc Behavioral Sci 2013; 99: 691-700.

2. Hasan I, Hoi CK, Wu Q, Zhang H. Is social capital associated with corporate innovation? Evidence from publicly listed firms in the US. J Corporate Finance 2020; 62: 101623.

3. Zhang Q, Pan J, Jiang Y, Feng T. The impact of green supplier integration on firm performance: The mediating role of social capital accumulation. J Purchasing Supply Manag 2020; 26(2): 100579.

4. Takhsha M, Barahimi N, Adelpanah A, Salehzadeh R. The effect of workplace ostracism on knowledge sharing: the mediating role of organization-based self-esteem and organizational silence. J Workplace Learn 2020; 32(6): 417-35.

5. Oduyoye FO. Debate on the role of organizational silence behaviors and employee efficiency. Global J Manag Busin Res 2020; 20(6): 1-9.
6. Delery JE, Roumpi D. Strategic human resource management, human capital, and competitive advantage: is the field going in circles? Hum Resour Manag J 2017; 27(1): 1-21.

7. Nankervis A, Baird M, Coffey J, Shields J. Human resource management. Canberra: Cengage Australia; 2019.

8. Tang G, Chen Y, Jiang Y, Paille P, Jia J. Green human resource management practices: scale development and validity. Asia Pac J Hum Resour 2018; 56(1): 31-55.

9. Lincoln YS, Guba EG. But is it rigorous? Trustworthiness and authenticity in naturalistic evaluation. New Dir Prog Eval 1986; 30: 73-84.

10. Danaee Fard H, Panahi B. An analysis of employee's attitudes in public organizations: Explanation of organizational silence climate and silence behavior. Transform Manag J 2010; 2(3): 1-19 [In Persian].

11. Damghanian H, Rouzban F. Explaining employee silence in connection with the direct manager based on mixed method. Organ Behav Stud Quart 2015; 4(3): 194-75 [In Persian].

12. Farjam S, Almodarresi SM, Pirvali E, Saberi H, Malekpour S. The mediator effect of occupational burnout on the relationship between organizational cynicism and organizational silence (Case of study: employees of Farokhshahr social security organization hospital). Rev Publicando 2018; 5(15): 1136-59.

13. Beyran Nejad A, Davari E, Afkhami M. Organizational silence as a current challenge in human resource management: exploring the factors and consequences. Organ Behav Stud Quart 2017; 6(1): 147-76 [In Persian]. 